\title{
PILOT SURVEY ON CASES OF POISONING AND ITS OUTCOME IN DIFFERENT CATEGORY OF HOSPITALS IN BANGLADESH
}

\author{
M ROBED AMIN ${ }^{1}$, ANISUL AWWAL ${ }^{2}$, M.ABDUSSATTAR ${ }^{3}$, RAFIQUL HASAN ${ }^{4}$, RABIUL ISLAM ${ }^{5}$, MA JALIL $^{6}$, \\ MD. ABUL KASHEM KHANDAKER ${ }^{7}$, MA FAIZ ${ }^{8}$
}

\section{Introduction:}

Poisoning and snakebite are commonly encountered emergency situation in Bangladesh. Morbidity per annum reported from static primary health care set up and district hospitals following poisoning are $0.56 \%$ of total morbidity. Reports published from the DGHS in 2001 recorded poisoning as fifteenth cause of morbidity \& second commonest cause of death second to acute respiratory tract infection (1956). ${ }^{1}$ Common poisoning encountered in the community include pesticide poisoning, kerosene poisoning, poisoning by unknown sedative substances for stupefying purpose and with occasional reports of methanol poisoning, aluminium phosphide poisoning, copper sulphate poisoning and puffer fish poisoning. A change in the trends of poisoning particularly 'travel related' poisoning by sedatives instead of previously used 'Dhatura' have been found in the country.

In the health service data, information from referral hospitals are not so far included. In one tertiary care hospital alone, Chittagong Medical College Hospital more than 1000 cases of poisoning and 400 cases of snakebite were reported in one year, 2002. ${ }^{2}$ 0ne hundred ten cases of death following poisoning were reported from the same hospital in $2001 .^{3}$ Available information gathered through two studies, one of them sponsored by the World Health Organization, demonstrated around 8000 cases of snake bite with $20 \%$ deaths-one of the highest record of the world. Mortality following a common poisoning, pesticide poisoning has been found to be $14-15 \%$ in comparison to less than $1 \%$ in the developed world. Prospective information through recording of cases could detect number and death of cases of poisoning in Bangladesh. In this communication an attempt was made to document all cases of poisoning attending different category of limited number of hospitals in Bangladesh for a defined period.

\section{Methodology \\ Study site- Two upazilla health complex (Hathazari and Sitakundu in Chittagong), one district hospital (Coxsbazar) and one Internal Medicine unit of Dhaka Medical College Hospital, Dhaka, Bangladesh.}

Study period: Three months from $1^{\text {st }}$ May to $31^{\text {st }}$ July, 2005.

Methods: All cases of poisoning including snakebite admitted in the study hospitals during the study period was recorded in a Poisoning Register. The register was developed as a part of an early application by one of the author (Mohammad Abul Faiz) and finalized through a number of meetings amongst the clinicians working in the study hospitals. The register was thus prepared. One doctor from each study site was selected as a responsible person. Training was arranged for the responsible persons for creating uniformity in keeping the register. All poisoning cases including snakebites was recorded in the register. The outcome of the cases was also recorded.

Data from the register was entered in a data base by a data entering clerk. At the end of the entry data was analyzed and a report was prepared.

Ethical aspect: As the register recorded data from hospitalized cases and no individual information was disclosed, so no ethical issue was related.

1. Assistant Professor of Medicine, Dhaka Medical College, Bangladesh

2. Postgraduate Student, Department of Cardiology (MD $3^{\text {rd }}$ Part), BSMMU, Bangladesh

3. Assistant Professor of Medicine, Chittagong Medical College, Bangladesh

4. Indoor Medical Officer, Department of Medicine, Dhaka Medical College \& Hopspital

5. Postgraduate Student, Department Of Medicine (MD $3^{\text {rd }}$ part),BSMMU, Bangladesh

6. Professor of Statistics, Department of Statistics, University of Dhaka, Bangladesh

7. Professor and Head, Department of Medicine, Dhaka Medical College Hospital ,Bangladesh

8. Professor of Medicine and Director General, Directorate General of Health Service, Dhaka, Bangladesh

Correspondence : Dr. M. Robed Amin, Assistant Professor of Medicine, Dhaka Medical College, Bangladesh 
Funding source: The study did not receive any fund from any source.

\section{Results}

During a period of three months May-July 2005, 397 cases of poisoning including snake bites were recorded in four different study sites involving different category of hospitals in Bangladesh. Most of the patients were male (62\%), muslim (90.4\%) and from the rural community (60\%). The mean age (+/- SD, yrs) of the patients were $26(+/-13)$ with a wide variation in range $1-80($ median $=25)$.

Table-I

Name of the poisoning $(n=397)$

\begin{tabular}{lcc}
\hline Poisoning & Frequency & Percent \\
\hline Pesticide & 113 & 28.5 \\
Benzodiazepine & 41 & 10.3 \\
Kerosene & 20 & 5 \\
Snake bite & 27 & 6.8 \\
CuSO $_{4}$ & 2 & 0.5 \\
Other sedative & 16 & 4 \\
Methanol & 1 & 0.3 \\
Other/Unknown & 172 & 43.3 \\
Rat Killer & 1 & 0.3 \\
Missing Data & 3 & 0.8 \\
\hline
\end{tabular}

The important substances involved and nature of poisoning were: organophosphorus compound poisoning (113, 28.5\%), benzodiazepine poisoning (41, $10.3 \%)$, snake bite $(27,6.8 \%)$, kerosene poisoning (20, $5 \%$ ), and poisoning by unknown substances (172, 43.3\%) (Table-I). Out of the 397 cases of poisoning, the information of nature of poisoning were available in 392 which showed intentional poisoning for self harm in 231 cases (58\%), homicidal in 87 cases (21.9\%), and accidental in 74 cases (18.6\%). (Fig.-1)

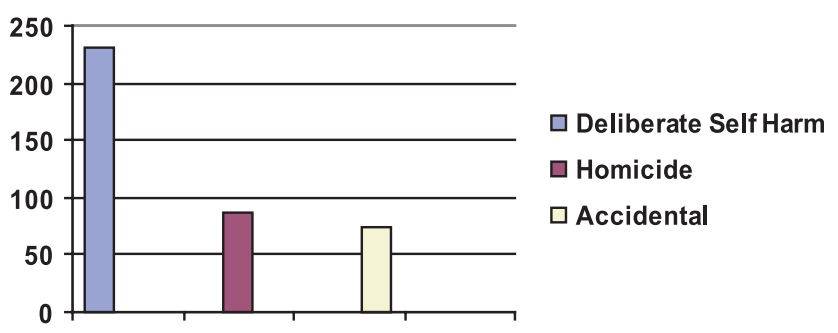

Fig.-1: Types of Poisoning ( $n=392)$
The pattern of poisoning varied in major types of poisoning: in OPC poisoning $65 \%$ patients were male, and had a motive of self harm in $88.4 \%$ cases; in kerosene poisoning most of the victims were relatively young children, mean age 4.5 years, and the poisoning was accidental in nature. The unknown substances were documented as agent of poisoning ( all but one were male) while the victims were traveling from one place to the other using public transport or by using own transport like 'rickshaw' or tri wheeler taxi. They were left in the emergency room of the hospital as an unknown person without any accompanying attendant in most of the occasion. Forty seven percent of victims of 'travel related' poisoning were recorded to be due to homicidal poisoning.

Among the cases of poisoning 323 (81.4\%) survived, 18 (4.5\%) patients died (Fig.-2). Forty six patients left hospital by their own without informing the hospital health professionals, most of them were travel related poisoning. Information about 10 patients referred from upazilla and district hospital to the tertiary referral hospital was not available.

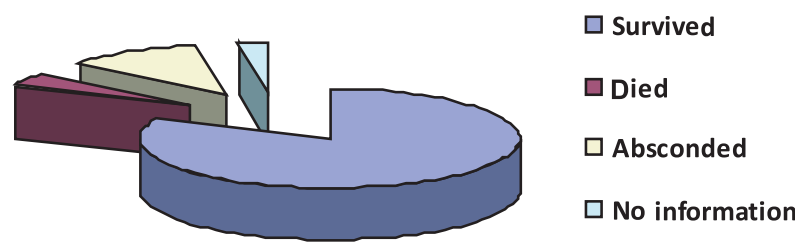

Fig.-2: Outcome of Poisoning ( $n=397)$

\section{Discussion:}

Most of the victims of poisoning were young adults from rural community suggesting an important acute health conditions of productive age group in rural Bangladesh. The substances used for poisoning were mostly OPC, 'unknown' substances, benzodiazepine, snake bite, kerosene.

Availability of cheap pesticide within the easy reach of rural farming household could contribute to their often use as agent of self harm. In fact most deaths are happening following poisoning in whole range of Asia Pacific following deliberate ingestion of various pesticides. ${ }^{4}$ The easy availability and delayed referral and hence delayed atropinasition can lead to danger and fatality may ensued. ${ }^{5}$ In order to make sensible use of pesticide each country should have a limited number of such agents and much public health awareness are needed for reducing deaths. 
The change in trends of 'travel related' poisoning was found in the Indian sub-continent with use of quickly acting sedatives presumably benzodiazepine. ${ }^{6}$ Such cases of intentional poisoning were found mostly in tertiary care hospital in this study possibly due to active group of organized criminals in the transport network of cities without hindrance from responsible travel authorities or law enforcing agencies. It emerged as an important social health problem affecting individually and socially besides economic loss of the victim. It was fortunate that no such patient died in this series as also documented in a recently conducted study in DMCH (Mahbub, 2004). Simple individual awareness of 'safe travel' particularly refraining from eating while on travel could prevent such 'homicidal' poisoning. Increased human snake interaction in highrisk group like farmers, housewives, fisherman, woodcutters, snake charmers particularly during harvesting season, and floods could cause snake envenomation as an important health hazard whole over country. ${ }^{7}$

The outcome of 10 referred cases could not be known. It is likely that they were serious cases requiring further intervention not available in place. A number of referrals within 3 months indicated need for a good formal referral system including care on transfer in the country. Eighteen deaths within a period of three months from a few hospital service area indicates a huge problem of poisoning in the country and justifies country wide actions for its prevention and appropriate treatment. Along with appropriate logistics, creation of knowledgeable health professionals is prerequisite for optimum management of poisoning. Before such actions are contemplated creation of evidence by recording cases of poisoning and snake bite should be performed in a Poisoning Register to be kept and maintained in adult and pediatric units in major hospitals in Bangladesh.

\section{Acknowledgements:}

The authors gratefully acknowledge the kind support of all members of the health professionals of the study hospitals for management of the cases.

\section{References:}

1. DGHS (2001). Bangladesh Health Bulletin 1998 99:11-12.

2. Year Book of the Department of Medicine, Chittagong Medical College,Chittagong, Bangladesh. 2002: 44-45

3. A Programme to establish a Poison Information Center in Bangladesh. Final Draft. Dr. M A Bari (Updated by Professor M Abul Faiz) (2003):1-2

4. World Health Organization (1990). Public Health Impact of Pesticides Used in Agriculture. WHO. Geneva.

5. Eddleston M, Buckley N A, Mohamed F . (2004). Speed of initial atropinisation in significant organophosphorus pesticide poisoning - a comparison of recommended regimens. Journal of Toxicology, Clinical Toxicology 42, 865-875.

6. M. J .Uddin, G.Hoque, F.Islam, S.Das, B.Islam .Transport related poisoning-an untapped public health problem, , Healer,2003;8:31-33.

7. Bangladesh journal of zoology, 1995; 23: 61-64 